\title{
Absent Fathers as Providers: Race/Ethnic Differences in Support for Adolescent Mothers
}

\author{
Constance M. Wiemann, Carolyn A. Agurcia, \\ Vaughn I. Rickert, Abbey B. Berenson, \\ and Robert J. Volk
}

ABSTRACT: Race/ethnic differences in the prevalence of and characteristics associated with low support provided by fathers of babies born to pregnant adolescents were examined among 719 adolescent mothers who were interviewed postpartum. Low support was reported by $41.9 \%$ of AfricanAmerican, 26.2\% of Mexican-American, and 19.4\% of Caucasian adolescent mothers. Across race/ethnic subgroups, fathers who provided limited support were characterized by chronic substance use, gang or police involvement, or partner-directed violence. Policies advocating universal father involvement without concomitant programs designed to address their many needs may ultimately be detrimental to the welfare of mother and child.

KEY WORDS: Adolescent mothers; Adolescent fathers; Social support; Adolescent pregnancy.

Constance M. Wiemann and Carolyn A.Agurcia are affiliated with Section of Adolescent Medicine \& Sports Medicine, Department of Pediatrics, Baylor College of Medicine, Houston, Texas.Vaughn I. Rickert is affiliated with Center for Community Health and Education, Heilbrunn Department of Population and Family Health, Mailman School of Public Health at Columbia University, New York. Abbey B. Berenson Division of Pediatric \& Adolescent Gynecology, Department of Obstetrics \& Gynecology, The University of Texas Medical Branch at Galveston, Texas. Robert J. Volk is affiliated with Department of Family and Community Medicine, Baylor College of Medicine, Houston, Texas. Address correspondence to Constance M. Wiemann, Department of PediatricsSection Adolescent Medicine \& Sports Medicine, Baylor College of Medicine, 6621 Fannin Street, Mail Station CC1710, Houston, TX 77030-2399, USA; e-mail: cwiemann@bcm.tmc.edu 


\section{Introduction}

Parenting by an adolescent mother is more effective when she has strong social and emotional support from her family and the child's father (Elster, McAnarney, \& Lamb, 1983; Lamb, 1981; Parke, Power, \& Fisher, 1980; Seymore, Frothingham, MacMillan, \& DuRant, 1990; Unger \& Cooley, 1992). In fact, partner support is associated with higher maternal self-esteem (Unger \& Wandersman, 1988) and inversely correlated with depressive symptomatology (Turner, Grindstaff, \& Phillips, 1990). In addition, paternal participation may directly influence a mother's ability to parent through shared care taking responsibilities and the provision of financial support, and may indirectly influence it through decreased maternal stress and improved maternal satisfaction (Elster et al., 1983; Lamb, 1981; Parke et al., 1980; Rivara, Elster, \& Panzarine, 1981). However, fewer than half of adolescent mothers receive any type of financial support from their babies' fathers (Roye \& Balk, 1996).

A young father's willingness or ability to take responsibility for his child may be influenced by his own age, socioeconomic status, education, self-image, coping system, self-expectations, and perceptions of fatherhood (Christmon, 1990; Elster, Lamb, \& Kimmerly, 1989; Hardy \& Duggan, 1989; Rivara et al., 1981; Seymore et al., 1990). The duration and stability of a father's relationship with his child's adolescent mother and his involvement in pregnancy planning and decision-making also influence his commitment to parenting (Elster et al., 1989) Finally, family disapproval (Cox \& Bithoney, 1995) or emotional distancing (Cervera, 1991) may discourage an otherwise interested father from having an ongoing relationship with his child and the adolescent mother.

Data suggest that fathers of babies born to adolescent mothers differ by race/ethnicity in personal characteristics and in the amount of support they provide. For example, African-American men father children at younger ages and more often outside of marriage than males of other ethnic backgrounds (Clark, Zabin, \& Hardy, 1984; Marsiglio, 1987; Rivara, Sweeney, \& Henderson, 1987). Yet the amount of contact between adolescent fathers and their children is much greater than has been commonly assumed, especially among African-American fathers (Furstenberg, Brooks-Gunn, \& Morgan, 1987; Furstenberg, Jr., 1976; Marsiglio, 1987). Fathering roles are influenced by sub-cultural norms and familial supports which could explain the greater tendency for African-American adolescent fathers 
as compared to White fathers to remain in and complete high school (Hardy \& Duggan, 1989) and Mexican-American fathers to marry their children's mothers (Felice, Shragg, James, \& Hollingsworth, 1987). Race/ethnic differences have also been reported in the wanting of pregnancies among adolescent mothers with Hispanics (Smith, McGill, \& Wait, 1987) more often than other races or ethnicities and African-Americans least likely (Ford, 1983; Mott, 1986) to indicate pregnancies were wanted. Moreover, the needs of young African American, Hispanic and Caucasian fathers have been found to vary both within and across cultures (Hendricks, 1988).

Given the importance of fatherhood, and the need to be culturally sensitive when designing interventions to promote healthy development of children born to adolescent mothers, information on race/ ethnic differences in the provision of paternal support and in the behaviors associated with low levels of support is needed. Prior research in this area has relied on small sample sizes (Barret \& Robinson, 1982; Elster et al., 1983; Elster \& Panzarine, 1980, 1981; Panzarine \& Elster, 1983; Zayas \& Schinke, 1987) or has had limited race/ethnic diversity (Elster et al., 1983; Panzarine \& Elster, 1983). The purpose of this study was to identify race/ethnic differences in the prevalence of support from fathers of babies born to pregnant adolescents. A second purpose was to examine in greater detail attributes of the father and relationship characteristics associated with low financial, informational, and emotional support at delivery. This information could inform the kinds of culturally sensitive interventions that may help fathers to remain involved with their children and their children's mothers.

\section{Methods}

All adolescent mothers through 18 years of age who delivered a healthy infant at The University of Texas Medical Branch-Galveston, between April 1994 and February 1996, were eligible to participate if they met the following criteria: self-reported Mexican-American, African-American, or Caucasian race/ethnicity; plan to retain custody of their infant; ability to read and write at a fifth grade level in either English or Spanish; absence of major psychiatric disorders; delivery of a healthy infant weighing $>1,500 \mathrm{~g}$; and were not intimately involved with anyone other than the fathers of their babies at delivery. Adolescents from other race/ethnic groups were excluded 
from study participation because of their low numbers. During the study period, 816 adolescents delivered an infant and were eligible to participate. Of these, 20 adolescents were not approached because of the large number of births on the day that they delivered. Of the 796 adolescents invited to participate, $72(9 \%)$ refused. The most common reason for declining to participate was not having enough time to complete the hour-long interview. An additional five subjects did not provide information on the amount of support provided by the fathers of their babies: three refused, with one stating she had been raped and did not want to answer these questions, and two reported the father had passed away. Therefore, the study sample included 719 adolescents: 286 Mexican Americans, 217 African Americans, and 216 Caucasians. Comparisons of demographic factors between those who refused and those interviewed revealed only one significant difference: a higher refusal rate among Mexican Americans who spoke only Spanish $(p<0.001)$.

\section{Procedures}

Each subject was interviewed in private for about an hour in either English or Spanish on the postpartum ward within 48 hours of delivery. Data were collected as part of a larger study of substance use among pregnant and parenting adolescents (Wiemann, DuBois, $\&$ Berenson, 1998). Written consent to participate was obtained from each subject and from the parent or legal guardian of those under 18 years of age who were living with their parents and not legally married, per Institutional Review Board regulations and approval.

Interview data obtained from the adolescent mother included characteristics of the baby's father: age; race/ethnicity; school enrollment and education completed; employment; gang membership; involvement with the police or courts ("Has the father of your baby ever been involved with the police or courts? [i.e., arrested, warrants, boy's home, convicted of a crime, etc.]"); and substance use. Relationship parameters included the amount of financial, informational, and emotional support provided by the father at delivery; whether the pregnancy was planned; the length and current status of their relationship; whether contact between them was prevented by her parents; whether the adolescent mother wanted the father to be her lifelong partner ("I would like the father of my baby to be my boyfriend/husband for the rest of my life."); and partner-directed violence. 
Questions on partner-directed violence, partner substance use, and partner support have been described previously (Wiemann, Agurcia, Berenson, Volk, \& Rickert, 2000). On a 5-point Likert scale from "Always True" to "Never True," each participant was asked to rate the level of support currently provided by the father of her baby in the areas of money, transportation, advice and information, encouragement for being a good mother, and being available to talk with about troubles. A total support score was derived by summing all five items (Cronbach coefficient $\mathrm{P}=0.85$ ); scores were then dichotomized so that those scoring in the lowest quartile could be compared to those scoring in the upper $75 \%$.

\section{Statistical Analyses}

Father and relationship characteristics were compared among subjects grouped by race/ethnicity (Mexican American, African American, and Caucasian) using chi-square and analysis of variance. Adolescents who reported more than one race/ethnicity were asked to choose the one with which they identified most closely. Continuous variable distributions were evaluated for assumptions of normality and homogeneity of variance. Sheffe post hoc tests were used to isolate groups that differed significantly. To identify important factors related to the provision of low support by the fathers, father and relationship characteristics were compared between fathers who provided low support with those who provided medium-to-high support within each race/ethnic subgroup. Bivariate correlates of low support $(p \leq 0.10)$ were then considered for entry into stepwise logistic regression analyses to identify factors independently associated with the outcome. Multi-colinearity was evaluated by examining correlations among independent variables.

\section{Results}

Fathers of babies born to African American mothers were significantly younger than fathers of babies born to Mexican American or Caucasian adolescent mothers (Table 1). In addition, they were most likely to be enrolled in school at the time of delivery, to be a member of a gang, to use alcohol or marijuana regularly, and to be in jail at the time of delivery. Caucasian mothers were more likely than 


\section{TABLE 1}

\section{Significant Differences in Father and Relationship Characteristics Among Adolescent Mother Race/Ethnic Groups}

\begin{tabular}{|c|c|c|c|c|}
\hline & \multicolumn{4}{|c|}{ Adolescent Mother's Race/Ethnicity } \\
\hline & $\begin{array}{l}\text { Mexican } \\
\text { Americana } \\
(n=286)\end{array}$ & $\begin{array}{c}\text { African } \\
\text { American } \\
(n=217)\end{array}$ & $\begin{array}{l}\text { Caucasian } \\
(n=216)\end{array}$ & p-value \\
\hline \multicolumn{5}{|l|}{ Father Characteristic } \\
\hline Age (year, mean \pm SD.) & $20.3 \pm 3.57$ & $19.9 \pm 3.95$ & $20.3 \pm 3.77$ & $<0.001$ \\
\hline Race/ethnicity & & & & $<0.001$ \\
\hline Mexican-American & $86.4 \%$ & $3.2 \%$ & $19.8 \%$ & \\
\hline African-American & 4.9 & 94.0 & 10.1 & \\
\hline Caucasian & 5.9 & 1.4 & 68.7 & \\
\hline High school diploma/G.E.D. & 30.8 & 50.0 & 49.5 & $<0.001$ \\
\hline Enrolled in school & 18.5 & 35.9 & 20.5 & $<0.001$ \\
\hline Employed & 77.8 & 49.2 & 77.0 & $<0.001$ \\
\hline Gang membership & 5.7 & 10.2 & 1.9 & 0.001 \\
\hline Police involvement & 41.2 & 57.6 & 53.0 & 0.001 \\
\hline Currently in jail & 2.8 & 7.4 & 3.2 & 0.029 \\
\hline \multicolumn{5}{|l|}{ Substance use } \\
\hline Tobacco (daily use) & 22.4 & 17.6 & 49.3 & $<0.001$ \\
\hline Alcohol ( $\geq$ weekly) & 5.7 & 16.5 & 6.6 & $<0.001$ \\
\hline Marijuana ( $\geq$ weekly) & 10.5 & 24.5 & 10.8 & $<0.001$ \\
\hline \multicolumn{5}{|l|}{ Relationship Characteristic } \\
\hline Father provides low support & 26.2 & 41.9 & 19.4 & $<0.001$ \\
\hline Relationship & & & & $<0.001$ \\
\hline Non romantic & 16.4 & 32.1 & 14.3 & \\
\hline Dating & 21.0 & 49.5 & 13.4 & \\
\hline $\begin{array}{l}\text { Engaged, married } \\
\text { or living together }\end{array}$ & 62.6 & 18.3 & 72.4 & \\
\hline Unplanned pregnancy & 73.1 & 90.8 & 80.2 & $<0.001$ \\
\hline $\begin{array}{l}\text { Mother wants father } \\
\text { to be lifetime partner }\end{array}$ & 86.6 & 64.5 & 84.7 & $<0.001$ \\
\hline
\end{tabular}

Note. 20 Mexican American, 22 African-American, and 12 Caucasian adolescent mothers did not know whether their babies' fathers were employed. 
mothers in the other groups to report that the fathers of their babies were of a different race/ethnic background than themselves and that the fathers of their babies smoked tobacco. Fathers of babies born to Mexican American adolescent mothers were least likely to have a high school diploma or to have received a G.E.D. or to report prior involvement with the police or courts.

African American mothers were more likely than Mexican Americans and Caucasians to report low support from the fathers of their babies and to report that their current pregnancy was unplanned (Table 1). They were least likely to report being engaged or married to or living with the fathers of their babies and also least likely to report that they wanted the fathers of their babies to be their lifetime romantic partners. No differences among race/ethnic groups were observed in the mean length of their relationship with the fathers of their babies, in the proportions who reported being in a romantic relationship with the fathers of their babies for more than 12 months prior to delivery, in the prevalence of partner-directed violence, or in fathers' use of illicit drugs other than marijuana.

Comparing father characteristics between adolescent mothers who reported that the fathers of their babies provided low as compared to medium-to-high support within each race/ethnic group identified several important correlates of low support (Table 2). Not having received a high school diploma or G.E.D. was associated with low support among African Americans only. Gang membership predicted low father support between both Mexican American and African American adolescent mothers while police involvement or current residence in jail was associated with low support among Caucasians only. Fathers' use of alcohol or marijuana on a weekly or more frequent basis and fathers' not being employed was associated with low support among all three race/ethnic groups. His use of any other illicit drug was associated with low support among Mexican American and Caucasian adolescent mothers while his daily use of tobacco was associated with low support among Mexican Americans only.

Several characteristics of the relationship between the mother and father of her baby also were significantly associated with low father support (Table 3). Across all race/ethnic groups, low father support was associated with a relationship of 12 months or less, a current relationship described as non romantic, infrequent contact with the father, and perceived abandonment of the father upon learning that his partner was pregnant. Partner-directed violence was associated with low father support among both Mexican American and 


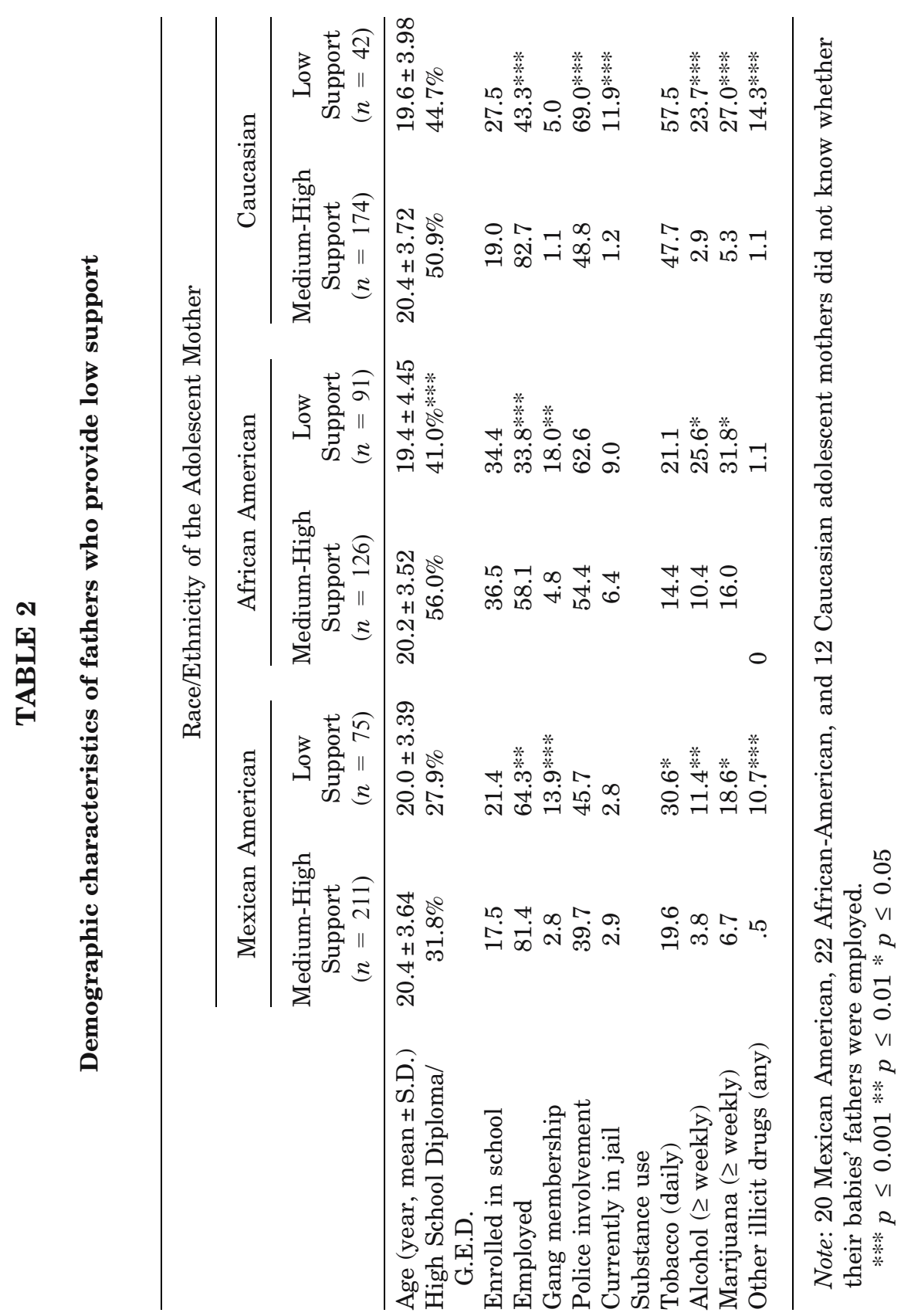




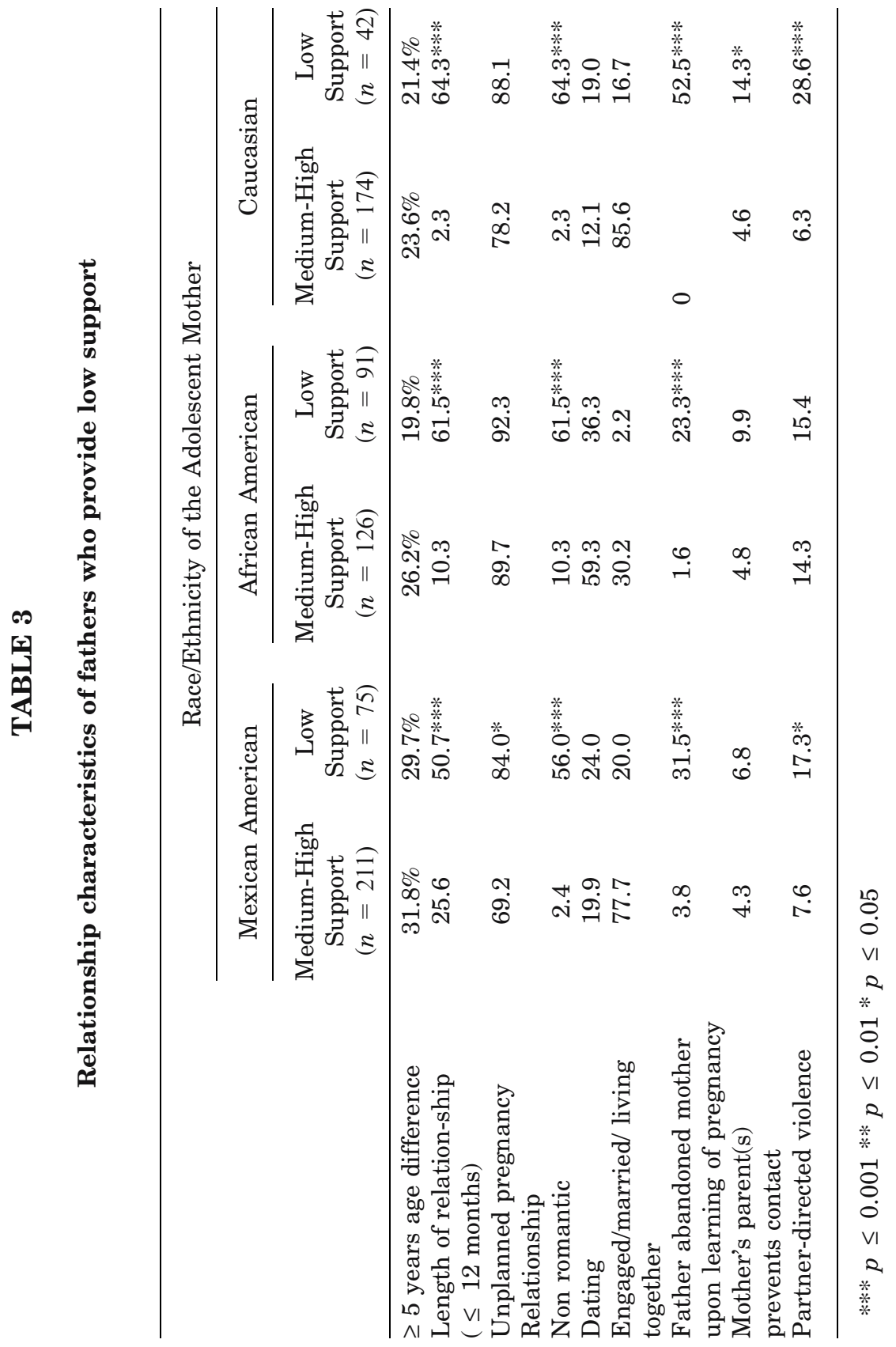


Caucasian mothers. An unplanned pregnancy was associated with low father support among Mexican Americans only. Prevention of contact between the adolescent mother and the father of her baby by the female's parents was associated with low father support only among Caucasian adolescent mothers.

Stepwise logistic regression was used to identify factors independently associated with low father support within each race/ethnic subgroup (Table 4). Because of a significant correlation $(r>0.50)$ with low support, perceived abandonment by the father of her baby and type of relationship were not included in these analyses. Also not included was father employment due to the relatively large number of missing values for this variable. Father's use of alcohol on a weekly or more frequent basis and a relationship of $\leq 12$ months duration prior to delivery were important predictors of low support

\section{TABLE 4}

\section{Logistic regression models of low father support for each race/ethnic group}

\begin{tabular}{|c|c|c|c|c|c|}
\hline & \multicolumn{5}{|c|}{ Adolescent Mother's Race/Ethnicity } \\
\hline & \multicolumn{2}{|c|}{$\begin{array}{l}\text { Mexican } \\
\text { American }\end{array}$} & \multicolumn{2}{|c|}{$\begin{array}{l}\text { African } \\
\text { American }\end{array}$} & Caucasian \\
\hline & AOR & $95 \% \mathrm{CI}$ & AOR & $95 \% \mathrm{CI}$ & AOR $95 \%$ CI \\
\hline \multicolumn{6}{|l|}{ Father Characteristic } \\
\hline Alcohol use ( $\geq$ weekly) & 3.7 & $1.2-11.1$ & 2.4 & $1.1-5.4$ & $6.8 \quad 2.0-23.9$ \\
\hline $\begin{array}{l}\text { Use of illicit drugs other } \\
\text { than marijuana }\end{array}$ & & & & & $7.5 \quad 1.2-45.4$ \\
\hline Gang membership & & & 3.5 & $1.2-9.8$ & \\
\hline \multicolumn{6}{|l|}{ Relationship characteristic } \\
\hline Unplanned pregnancy & 2.6 & $1.3-5.4$ & & & \\
\hline Relationship $\leq 12$ months & 2.7 & $1.5-4.8$ & 2.9 & $1.6-5.3$ & $2.6 \quad 1.1-5.8$ \\
\hline Partner-directed violence & 3.3 & $1.4-7.8$ & & & \\
\hline $\begin{array}{l}\text { Mother's parent(s) } \\
\text { prevents contact }\end{array}$ & & & & & $4.1 \quad 1.2-14.2$ \\
\hline
\end{tabular}

AOR $=$ Adjusted odds ratios 95\%.

$\mathrm{CI}=95 \%$ Confidence Interval. 
across race/ethnic groups. An unplanned pregnancy and partnerdirected violence were also important predictors of low support among Mexican Americans while partner's membership in a gang was a strong predictor among African Americans. Additional predictors among Caucasians included father's use of illicit drugs beyond marijuana and prevention of contact by the mother's parent(s).

\section{Discussion}

According to maternal report, almost three-quarters of the fathers in our study provided moderate to high support to the mothers of their babies at the time of delivery. These rates are somewhat higher than those reported in previous studies in which no more than half of adolescent mothers reported receiving any type of support from their babies' fathers (Rhein et al., 1997; Roye \& Balk, 1996). Differences in findings between this and other studies must be interpreted with caution as they may be due to diverse methods of measuring support and variation in the timing of assessment (e.g., at delivery versus the early postpartum months) rather than actual differences in levels of support received.

By investigating a multi-race/multi-ethnic group of adolescents, we were able to examine differences by race/ethnicity in the characteristics of the fathers of their babies and in the relationships between the mothers and fathers. Similar to other research, (Marsiglio, 1987; Unger \& Cooley, 1992) we noted that African-American mothers were more likely to report low support from their partners who were themselves largely African American. Furthermore, the male partners of the African American women were younger and the least likely to be employed. This association between providing inadequate support for their children, young age, and living in poverty has been previously demonstrated; in fact, the most common reasons given by fathers for not living with their babies' mothers is that they are financially unable to or they are too young (Rivara, Sweeney, \& Henderson, 1986). We observed that partners of African-American mothers were more likely than the other two groups to be enrolled in school or have completed high school. African-American youth are often encouraged by families to remain in school, because of the costs - lower wages and fewer employment opportunities - of leaving school prematurely (Leashore \& Gary, 1984). 
A relationship length of 12 months or less at delivery was noted in 32.2\% of Mexican Americans, 33.5\% of African Americans, and $30.9 \%$ of Caucasians overall. This was an important predictor of low support across all three race/ethnic subgroups. Since the majority of pregnancies to young mothers in our sample like most previous studies (Hardy, Duggan, Mansnyk, \& Pearson, 1989) were unplanned, it is likely that many of these couples were not in committed relationships at the time of conception. Roye et al. reported that during pregnancy $33 \%$ of fathers-to-be were already seeing someone other than the mothers of their babies. In contrast, other studies demonstrate that many low-income African American males continue to show interest in their child and their child's mother even if they are not married or living together (Furstenberg, 1976; Klinman, Sanders, Rosen, \& Longo, Sullivan, 1985). The duration and stability of a father's relationship with his child's mother and his involvement in pregnancy planning and decision-making process also influence his commitment to parenting (Elster et al., 1989). While many studies have reported that fathers of babies born to adolescent mothers want to be involved with both the mother and child (Barret \& Robinson, 1982; Elster \& Lamb, 1986; Elster \& Panzarine, 1983a,b; Furstenberg et al., 1987; Hendricks, 1979; Lorenzi, Klerman, \& Jekel, 1977) limited experience as a couple prior to conception, along with poor interpersonal and couple-level communication skills, may prevent the type of dialog and accompanying behaviors that would foster a higher level of involvement.

Of interest was the finding that many African-American mothers did not want this father to be their lifetime partner. Many pregnant adolescents do not marry prior to delivery due to concerns about the stability of marriage (Furstenberg et al., 1987) rather than a desire to become single mothers. A study of African American and Hispanic adolescent mothers indicated that irresponsibility, restrictive or physically assaultive behaviors, use or selling of drugs, and entry into jail were common reasons why they did not remain in contact with their childrens' fathers (Leadbeater, Way, \& Raden, 1996). Furthermore, illegal activity has been reported to be common among partners of adolescent mothers: in one study, more than half of adolescent mothers reported that the fathers of their babies had used marijuana in the 30 days prior to the mothers being interviewed during pregnancy, 39\% said fathers had been involved in other illegal activities, while $39 \%$ reported that the fathers had sold drugs (Larson, Hussey, Gillmore, \& Gilchrist, 1996). Finally, a number of 
adolescent fathers physically assault their partners (Harrykissoon, Rickert, \& Wiemann, 2002; Wiemann et al., 2000). The negative influence of the partner may be particularly problematic when he is significantly older than the adolescent (Agurcia, Rickert, Berenson, Volk, \& Wiemann, 2001; Elster et al., 1989; Lamb, \& Tavare, 1986). Thus, many adolescent mothers may be limiting contact with their babies' fathers due to his behavior. Promoting relationships with all fathers without concomitant services to help alter problematic behavior may not be in the best interests of mother, father or child.

Chronic alcohol use predicted low support for fathers in all three subgroups while chronic marijuana use was important among partners of Caucasian mothers only. A variety of personality factors and behavioral patterns that have been identified among adolescent drug users are consistent with not taking responsibility for fatherhood. These include rebelliousness;(Block, Block, \& Keyes, 1988; Kandel, 1974); nonconformity to traditional values (Block et al., 1988; Jessor, 1975); high tolerance of deviance (Block et al., 1988; Brook, Lukoff, \& Whiteman, 1988; Jessor \& L., 1975); strong need for independence;(Block et al., 1988) normlessness, low self-control, and resistance to traditional authority and responsibility (Arkin \& Funkhouser, 1990). Because the fathers were not interviewed for this study, it is not possible to determine when abuse of harmful substances began, the true extent of use, or whether substances were used in response to emotional turmoil experienced as a result of premature fatherhood (Elster \& Panzarine, 1983a,b; Parker, 1971). Programs that address substance use are particularly important for this population because not intervening to reduce or eliminate the use of harmful substances may have adverse consequences for the baby's mother as well as the child. For example, others have reported substance use by pregnant adolescents to be higher when partners also used alcohol or other drugs (Wiemann, 1998; Gilchrist, Gillmore, \& Lohr, 1990). In addition, the risk of child maltreatment increases (Panzarine, 1986).

One of the more interesting findings was the importance of the adolescent mother's parents in preventing contact with the baby's father found among Caucasian adolescents only. Adolescent mothers frequently live with their own families during the first few years following birth (Cox \& Bithoney, 1995). Several prior studies of pregnant adolescents from various race/ethnic groups document negative reactions of family members toward the baby's father (Poland \& Giblin, 1982; Rivara et al., 1981; Vaz, Smolen, \& Miller, 1983) with 
families frequently not encouraging father involvement (Fein, 1976; May, 1982; Reiber, 1976; Rhein et al., 1997). For the families of some pregnant adolescents, prospective fathers are perceived as threatening to the newly found family closeness that the pregnancy has spawned (Cervera, 1991). Thus, some pregnant adolescents find themselves having to choose between parental support or support from their babies' fathers (Cervera, 1991). Having a supportive relationship between the adolescent mother's family and the father of her baby at two weeks postpartum predicted at least monthly contact between the baby's father and his child at 24 months in one prior study (Cox \& Bithoney, 1995). Thus, family disapproval, especially by the baby's grandmother, (Rhein et al., 1997) may discourage or inhibit a father's contact with his child, regardless of his own wishes. Interventions to promote father involvement must consider the important gate-keeping role played by the pregnant adolescent's family of origin.

There are several limitations to this study. First, all information on the fathers described herein came from interviews conducted with adolescent mothers. These young women may not have had accurate or complete information on substance use, or gang and police involvement or may have wanted to present the father in a more negative manner due to his limited involvement. Second, because fathers were not interviewed directly, reasons for the lack of involvement could not be evaluated. Moreover, the role of the adolescent mother in whether the father provided support was not examined. Third, because these data are cross-sectional, causal inferences between fathers' support and their correlates cannot be made. Finally, the sample used in this study was drawn from southeast Texas and findings may not generalize beyond this region of the country.

In summary, this study suggests that many fathers provide at least moderate support to their babies' adolescent mothers. However, an important cluster of fathers who exhibit antisocial characteristics such as substance abuse, gang or police involvement, and partner-directed violence provide limited financial, emotional, and social support. Programs and interventions that focus on building couple-level communication skills, improving skills to acquire better career opportunities, and screening and treatment for mental health problems may be key components to improve the ability of these fathers to provide support to their babies and to the adolescent mothers. Communication between the prospective father and the pregnant adolescent's family must also be addressed. Thus, policies 
advocating father involvement without concomitant programs intended to address their many needs may be doomed to fail and could ultimately be detrimental to the welfare of both mother and child.

\section{ACKNOWLEDGMENTS}

We are indebted to the many adolescent participants who shared their experiences with us and to the interviewers who spent hundreds of hours collecting this information. Supported by grants DA09636 and DA08404 from the National Institute on Drug Abuse and The Hogg Foundation for Mental Health (\#3777) (Dr. Wiemann). The findings presented herein do not reflect the views of either granting organization. Data were presented in part at the Annual Meeting of the Society for Adolescent Medicine, Arlington, VA, March 22, 2000.

\section{References}

Agurcia, C. A., Rickert, V. I., Berenson, A. B., Volk, R. J., \& Wiemann, C. M. (2001). The behavioral risks and life circumstances of adolescent mothers involved with older adult partners. Archives Pediatrics Adolescent Medicine, 155, 822-830.

Arkin, E. B., \& Funkhouser, J. E. (1990). Communicating about alcohol and other drugs: strategies for reaching populations at risk. Unpublished manuscript, Rockville, MD: National Clearinghouse for Alcohol and Drug Information..

Barret, R. L., \& Robinson, B. E. (1982). A descriptive study of teenage expectant fathers. Family Relations, 31(3), 349-352.

Block, J., Block, J. H., \& Keyes, S. (1988). Longitudinally foretelling drug usage in adolescence: early childhood personality and environmental precursors. Child Development, 59(2), 336-355.

Brook, J. S., Lukoff, I. F., \& Whiteman, M. (1988). Initiation into adolescent marijuana use. Jounal of Genetic Psychology, 137, 133-142.

Cervera, N. (1991). Unwed teenage pregnancy: family relationships with the father of the baby. Families in Society: Journal Contemporary Human Service, 72, 29-37.

Christmon, K. (1990). Parental responsibility of African-American unwed adolescent fathers. Adolescence, 25, 645-653.

Clark, S. D. Jr., Zabin, L. S., \& Hardy, J. B. (1984). Sex, contraception and parenthood: experience and attitudes among urban black young men. Family Planning Perspectives, 16(2), 77-82.

Cox, J., \& Bithoney, W. (1995). Fathers of children born to adolescent mothers. Archives of Pediatrics and Adolescent Medicine, 149, 962-966.

Elster, A., Lamb, M., \& Kimmerly, N. (1989). Perceptions of parenthood among adolescent fathers. Pediatrics, 83, 758-765.

Elster, A. B., Lamb, M. E. (1986). Adolescent Fatherhood. Hillsdale, NJ: Lawrence Earlbaum Associates. 
Elster, A. B., McAnarney, E. R., \& Lamb, M. E. (1983). Parental behavior of adolescent mothers. Pediatrics, 71(4), 494-503.

Elster, A. B., \& Panzarine, S. (1980). Unwed teenage fathers: emotional and health educational needs. Journal of Adolescent Health Care, 1(2), 116-120.

Elster, A. B., \& Panzarine, S. (1981). The adolescent father. Seminars in Perinatology, 5(1), 39-51.

Elster, A. B., \& Panzarine, S. (1983). Teenage fathers. Stresses during gestation and early parenthood. Clinical Pediatrics (Phila), 22(10), 700-703.

Elster, A. B., Panzarine, S. L. (1983). Adolescent Fathers. In G. Stratton (Ed.). Premature Adolescent Pregnancy and Parenthood (pp. 231-252). New York: McAnarney ER .

Fein, R. (1976). Men's entrance to parenthood. Family Coordinator, 25, 341-348.

Felice, M. E., Shragg, G. P., James, M., \& Hollingsworth, D. R. (1987). Psychosocial aspects of Mexican-American, white, and black teenage pregnancy. Journal of Adolescent Health Care, 8(4), 330-335.

Ford, K. (1983). Second pregnancies among teenage mothers. Family Planning Perspectives, 15, 268-272.

Furstenberg, F. F. (1976). Unplanned parenthood: the social consequences of teenage childbearing. New York: The Free Press, A Division of MacMillan Publishing Company, Inc..

Furstenberg, F. F., Brooks-Gunn, J., \& Morgan, S. P. (1987). Adolescent mothers and their children in later life. Family Planning Perspectives, 19(4), 142-151.

Furstenberg, F. F., Jr. (1976) The social consequences of teenage parenthood. Family Planning Perspectives 8(4):148-151.

Gilchrist, L. D., Gillmore, M. R., \& Lohr, M. J. (1990). Drug use among pregnant adolescents. Consulting and Clinical Psychology, 58, 402-407.

Hardy, J., \& Duggan, A. (1989). Teenage fathers and the fathers of infants of urban, teenage mothers. American Journal of Public Health, 78, 919-922.

Hardy, J., Duggan A., Mansnyk, K., Pearson C. (1989) Fathers of children born to young urban mothers. Family Planning Perspectives 21:159-163, 187.

Harrykissoon, S. D., Rickert, V. I., \& Wiemann, C. M. (2002). Prevalence and patterns of intimate partner violence among adolescent mothers during the postpartum period. Archives Pediatrics and Adolescent Medicine, 156(4), 325-330.

Hendricks, L. E. (1979). Unwed adolescent fathers: problems they face and their sources of social support. Adolescence, 15, 862-869.

Hendricks, L. E. (1988). Outreach with teenage fathers: a preliminary report on three ethnic groups. Adolescence, 23(91), 711-720.

Jessor, R., \& Jessor, S.L. (1975) Adolescent development and the onset of drinking: a longitudinal study. Journal of Studies on Alcohol 36:27-51.

Kandel, D. (1974). Inter and intergenerational influences on adolescent marijuana use. Journal of Social Issues, 30, 107-135.

Klinman, D. G., Sander, J. H., Rosen, J. L., Longo, K. R., \& Bank Street College of Education (1986). The teen father collaboration: a demonstration and research model. In A. B. Elster \& M. E. Lamb (Eds.), Teenage Fatherhood (pp. 155-170). Hillsdale: Lawrence Earlbaum Associates.

Lamb, M. E. (1981). Father and child development: an integrative overview. In M. E. Lamb (Ed.), The role of the father in child development $\left(2^{\text {nd }}\right.$ ed.) (pp 1-70). New York: John Wiley \& Sons.

Lamb, M.E., Elster, A.B., \& Tavare, J. (1986) Behavioral profiles of adolescent mothers and partners with varying intracouple age differences. Journal of Adolescent Research, 1(4), 399-408.

Larson, N., Hussey, J., Gillmore, M., \& Gilchrist, L. (1996). What about dad? Fathers of children born to school-age mothers. Families in Society: Journal of Contemporary Human Services, 77(5), 279-289. 
Leadbeater, B. J., Way, N., \& Raden, A. (1996). Why not marry your baby's father? Answers from African American and Hispanic adolescent mothers. In B. J. Leadbeater \& N. Way (Eds.), Urban girls: resisting stereotypes, creating identities (Vol. xvi, pp. 193-209) New york: Newyork University Press.

Leashore, B. R., \& Gary, L. E. (1984). Black males in white America: critical issues. In B. W. White (Ed.), Color in a white society (pp. 115-125). Silver Springs, MD: National Association of Social Workers.

Lorenzi, M. E., Klerman, L. V., \& Jekel, J. F. (1977). School-age parents: how permanent a relationship. Adolescence, 12(45), 13-22.

Marsiglio, W. (1987). Adolescent fathers in the United States: their initial living arrangements, marital experience and educational outcomes. Family Planning Perspectives, 19(6), 240-251.

May, K. A. (1982). Three phases of father involvement in pregnancy. Nursing Research, $31,337-342$.

Mott, F. L. (1986). The pace of repeated childbearing among young American mothers. Family Planning Perspectives, 18, 5-12.

Panzarine, S. (1986). Stressors, coping, and social supports of adolescent mothers. Journal of Adolescent Health Care, 7(3), 153-161.

Panzarine, S., \& Elster, A. B. (1983). Coping in a group of expectant adolescent fathers: an exploratory study. Journal of Adolescent Health Care, 4(2), 117-120.

Parke, R., Power, T., \& Fisher, T. (1980). The adolescent father's impact on the mother and child. Journal of Social Issues, 36, 88-106.

Parker, J. D. (1971). Fathers of children conceived out of wedlock: prepregnancy high school, psychological test results. Developmental Psychology, 4, 215-218.

Poland, M., \& Giblin, P. (1982). A preliminary study of the relationship between mothers' attitudes and their adolescent pregnancies (abstract). Contraceptive Delivery Systems, 3, 560.

Reiber, V. (1976). Is the nurturing role natural to fathers. American Journal of Maternal Child Nursing, 1, 336-371.

Rhein, L. M., Ginsburg, K. R., Schwarz, D. F., Pinto-Martin, J. A., Zhao, H., Morgan, A. P., \& Slap, G. B. (1997). Teen father participation in child rearing: family perspectives. Journal of Adolescent Health, 21(4), 244-252.

Rivara, F. P., Sweeney, P. J., \& Henderson, B. F. (1986). Black teenage fathers: what happens when the child is born. Pediatrics, 78, 151-158.

Rivara, F. P., Sweeney, P.J., \& Henderson, B.F. (1987). Risk of fatherhood among black teenage males. American Journal of Public Health, 77(2), 203-205.

Rivara, F.P. (1981). Teenage pregnancy: the forgotten father. Journal of Developmental Behavioral Pediatrics, 2, 142-145.

Roye, C. F., \& Balk, S. J. (1996). The relationship of partner support to outcomes for teenage mothers and their children: a review. Journal of Adolescent Health, 19(2), $86-93$.

Seymore, C., Frothingham, T., MacMillan, J., \& DuRant, R. (1990). Child development knowledge, childrearing attitudes, and social support among first and second time adolescent mothers. Journal of Adolescent Health, 11, 343-350.

Smith, P. B., McGill, L., \& Wait, R. B. (1987). Hispanic adolescent conception and contraception profiles. Journal of Adolescent Health Care, 8, 352-355.

Sullivan M. (1985) Teen fathers in the inner city: an exploratory ethnographic study. New York: Vera Institute of Justice.

Turner, R. J., Grindstaff, C. F., \& Phillips, N. (1990). Social support and outcome in teenage pregnancy. Journal of Health \& Social Behavior, 31(1), 43-57.

Unger, D., \& Cooley, M. (1992). Partner and grandmother contact in black and white teen parent families. Jounal Adolesc Health, 13, 546-552.

Unger, D., \& Wandersman, L. (1988). The relation of family and partner support to the adjustment of adolescent mothers. Child Development, 59, 1056-1060. 
Vaz, R., Smolen, P., \& Miller, C. (1983). Adolescent pregnancy: involvement of the male partner. Journal of Adolescent Health Care, 4(4), 246-250.

Wiemann, C. M., Agurcia, C. A., Berenson, A. B., Volk, R. J., \& Rickert, V. I. (2000). Pregnant adolescents: experiences and behaviors associated with physical assault by an intimate partner. Maternal Child Health Journal, 4, 93-101.

Wiemann, C. M., DuBois, J. C., \& Berenson, A. B. (1998). Racial/ethnic differences in the decision to breastfeed among adolescent mothers. Pediatrics, 101(6), E11.

Zayas, L. H., \& Schinke, S. P. (1987). Hispanic adolescent fathers: at risk and underresearched. Children Youth Services Review, 9, 235-248. 